\title{
Kant as Both Conceptualist and Nonconceptualist
}

\author{
SACHA GOLOB \\ King's College London \\ Email: sacha.golob@kcl.ac.uk
}

\begin{abstract}
This article advances a new account of Kant's views on conceptualism. On the one hand, I argue that Kant was a nonconceptualist. On the other hand, my approach accommodates many motivations underlying the conceptualist reading of his work: for example, it is fully compatible with the success of the Transcendental Deduction. I motivate my view by providing a new analysis of both Kant's theory of perception and of the role of categorical synthesis: I look in particular at the categories of quantity. Locating my interpretation in relation to recent research by Allais, Ginsborg, Tolley and others, I argue that it offers an attractive compromise on this important theoretical and exegetical issue.
\end{abstract}

Keywords: Kant, conceptualism, non-conceptualism, nonconceptualism, perception

\section{Introduction}

'Conceptualism' and 'nonconceptualism' are used across the philosophical literature in multiple, non-coextensive ways. Since the concern here is with Kant, I frame the debate using his terminology. I define nonconceptualism as the thesis that a subject may possess empirical intuitions of spatiotemporal particulars even if that subject entirely lacks conceptual capacities. I I use the term 'subject' broadly - one key instance of such 'subjects' will be non-rational animals. Let conceptualism be the thesis that nonconceptualism is false. The debate is also often presented in terms of perception: the conceptualist holds, and the nonconceptualist denies, that concepts 'have an indispensable role' even in 'the mere perceptual presentation of particulars in empirical intuition' (Griffith 2010: I99; similarly Allais 2009: 384 ). As I discuss in section 2, however, care is needed here: there is an important difference between contemporary uses of 'perception' and Kant's own employment of Perception and related terms. I will therefore use the definition given in terms of empirical intuitions. 
In this article I argue for two claims: (i) that Kant is a nonconceptualist; (ii) that in the case of normally functioning, adult humans, however, empirical intuitions are necessarily subject to categorical, and thus conceptual, synthesis. My proposal is thus intended in a spirit of compromise - hence the article's title. I am not literally claiming, of course, that Kant endorses both conceptualism and nonconceptualism; given my definitions, that would be contradictory. Rather, I hold that whilst he is a nonconceptualist, this position, once properly understood, can accommodate many of the motivations and commitments driving Kantian conceptualism. Let me say something more specifically about the relation between (i) and (ii). It is sufficient to validate nonconceptualism, as defined, if there are any subjects enjoying empirical intuitions in the complete absence of conceptual capacities; so nonconceptualism would be true if Kant understood non-rational animals (henceforth 'animals') in this fashion. But if that were established, two vital issues would remain. First, it would be crucial to clarify whether only such animals could have nonconceptual intentional states. Many contemporary nonconceptualists assume that their arguments apply unproblematically to humans: Heck, for example, motivates his position by asking his - presumably human - readers to '[c]onsider your current perceptual state' (Heck 2000: 489). So we need to understand why, once placed in a human context, Kant believes that empirical intuitions are necessarily accompanied by category use: given his nonconceptualism, this cannot be a direct condition on empirical intuitions themselves. In short, how can (ii) be true given (i)? As I will explain, my view of this is quite different from that of Allais, for example. Second, there is a widespread assumption that Kant's argument for the categories implies the falsity of nonconceptualism: As Ginsborg puts it:

The central line of thought [in the Transcendental Deduction] is that the objective validity of the categories depends on their having a role to play, not just in explicit judgment, but also in our perceptual apprehension of the objects about which we judge. (Ginsborg 2008: 69; similarly Bowman 20II: 42I-2, Grüne 20II: 465-6)

If the possibility of non-categorial intuitions, what Hanna called 'rogue' intuitions, is to be admitted anywhere within the Kantian system, even for animals, the implications of that move for the Analytic need to be appraised (Hanna 20II: 409). In short, how can (i) be true given (ii)? 
The article has two stages. First, in section 2 I offer a new account of the relations between intuition, consciousness and perception in Kant's work. I argue that this supports nonconceptualism both by fleshing out his picture of nonconceptual intentionality and by clarifying the limitations which he saw as inherent in such intentionality. Second, in sections 3-4 I focus on the categories and the principles. I argue here that nonconceptualism is compatible with the key thrust of the Deduction, and can thus accommodate one of the main motivations for conceptualism. In examining why that is the case, we will also see why normally functioning, adult human intentionality necessarily involves the categories.

Before getting underway, a few terminological and conceptual clarifications. Like Allais, my concern is with 'relative nonconceptualism', i.e. with a nonconceptualism defined in terms of the relation between a mental state, namely an empirical intuition, and the subject to whom it is ascribed (Speaks 2005: 360; Allais 2009: 386). I will not discuss 'absolute nonconceptualism', the thesis that there exists content which is of 'a different kind ... than beliefs, thoughts, and so on' (Speaks 2005: 360). I am sympathetic to the view that incongruent counterparts demonstrate such content, but that requires discussion of topics particularly motor intentionality - to which I cannot do justice here. More specifically, my concern is with the relationship between relative nonconceptualism and the intentionality of empirical intuitions. In other words, I agree that 'a plausible nonconceptualist interpretation of Kant' needs to establish the possibility of 'perceptual images of objects in which those objects are intentionally represented without being brought under concepts' (Ginsborg 2008: 68). Mere sensory awareness is not enough. Posy makes the same point in a semantic idiom when he defines conceptualism as the view that 'without categorical principles, our mental states cannot serve their semantic role as intuitions' (Posy 2000: I65). There are, of course, foundational issues regarding intentionality which I cannot address here: for example, whether perceptual content is Fregean, Russellian or some form of Evansian hybrid, and I remain neutral on these issues. Finally, conceptualism may take several forms. Suppose that whilst empirical intuitions make an irreducible contribution to intentionality, this is necessarily dependent on the contribution made by concepts. This would suffice to refute nonconceptualism as defined. One might also argue for a more radically conceptualist thesis whereby intuitions are actually reducible to concepts. But since the less radical, and surely exegetically more plausible, form of conceptualism would suffice to refute my position, I focus on it. 


\section{Intentionality, Consciousness and Perception: Kant's General Theory}

This section sets out what I will call Kant's 'general theory' of intentionality, consciousness and perception. The theory is 'general' in that it outlines certain structures common to both rational, sensible beings such as humans and to non-rational, sensible animals. As he puts it himself:

[A]nimals also act in accordance with representations (Vorstellungen) (and are not, as Descartes would have it, machines), and in spite of their specific difference, they are still of the same genus as human beings (as living beings). $(K U, 5: 464)^{2}$

My presentation of the 'general theory' supports nonconceptualism in two ways. First, and most obviously, it helps makes sense of Kant's thinking about the relation between humans and animals. As McLear observes, it is 'fairly uncontroversial that Kant believed non-human animals incapable of conceptual capacities' (McLear 20I I: 4). But what is striking is that Kant allows them far more than mere sensations. The Jäsche Logic, for example, states that animals are 'acquainted with objects' (kennen Gegenstände) and can 'represent something in comparison with other things both as to sameness and as to difference'; what they lack is only the ability to 'cognize' (erkennen), a capacity which requires both intuition and concept ( $\log$, 9: 64-5; $K r V$, AIo6). Elsewhere Kant suggests that an ox has an outer sense intuition of its stall ( $\mathrm{SvF}, 2: 59)$, and it is obviously hard to deny that animals are capable of representing, in at least a simplistic manner, the spatial movements of their prey (Allais 2009: 407). Second, the 'general theory' clarifies aspects of Kant's model of synthesis. This is important because that model is often taken to support conceptualism (for example, Posy 2000: I72). Kant himself states that 'all combination is an action of the understanding' and that apperception is 'the source of all combination' $\left(\mathrm{KrV}, \mathrm{B} \mathrm{I}_{3} \mathrm{O}\right.$; cf. $\left.\mathrm{B}_{3} 34-5, \mathrm{I}_{54}\right)$. As I will argue in both this section and the next, however, the interaction between different modes of synthesis is significantly more nuanced than this suggests.

I will now set out the 'general theory'; I then come back to its implications for nonconceptualism at the close of this section.

I begin with the empirical intuitions of outer sense: these represent 'objects as outside us and all as in space' $\left(K r V, \mathrm{~A}_{22} / \mathrm{B}_{37}\right)$. Within the set of such intuitions, Kant distinguishes between those which are conscious and those which are unconscious: the latter class, he stresses, is the 
larger (Anth., 7: 136). He introduces the relevant notion of consciousness using the following example: if I perceive a man, I must also represent those parts that constitute him 'since the representation of the whole $\ldots$ is composed of these partial ideas' (Anth., 7: I35). However, I am not typically conscious of those parts: I may see a man's face 'even though I am not conscious of seeing his eyes, nose, mouth etc.' (Anth., 7: I35). Kant refers to conscious mental states as 'perceptions' ( $\mathrm{rrV}, \mathrm{A}_{32} \mathrm{O} /$

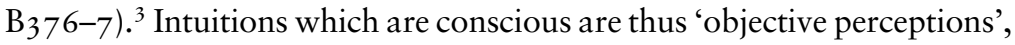
objective in that they 'refer' (sich beziehen) to an object (Gegenstand) (ibid.). I discuss the links between this formulation and talk of 'cognition' at the start of section 3 .

Before proceeding further, it is worth focusing on 'perception'. In the contemporary literature on nonconceptualism, 'perception' refers to sense perception, i.e. what we hear, see, taste, etc. Thus Heck's injunction to 'consider your current perceptual state', mentioned above, is followed by a list of things he can see (Heck 2000: 489-50). But Kant's use is quite different: perception is a 'representation with consciousness' ( $K r V, \mathrm{~A}_{32} \mathrm{O} /$

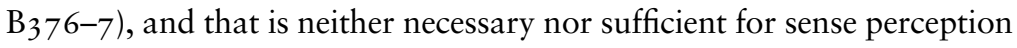
in the ordinary sense. It is not sufficient since a consciously occurrent thought about my house is a perception in Kant's terms, and it is not necessary since visual content may, as in the Anthropology example, be unconscious and thus not 'perceptual' in the Kantian sense. Nevertheless, the two meanings are not simply orthogonal to each other: empirical intuitions of outer sense, for example, are roughly analogous to perceptions in contemporary usage, and insofar as they are conscious these will also be perceptions in Kant's sense. For clarity's sake, I will use 'perception' only in its Kantian sense.

Kant's distinction between conscious and unconscious representational content raises an obvious question: what determines what I am conscious of? This can clearly vary: most of us are not typically conscious of other people's eyebrows, yet we may obviously become so (perhaps on reading that sentence). To answer this question, we need to turn to Kant's account of time. Kant defines time as 'nothing but the form of inner sense, i.e. of the intuition of ourself and our inner state' $\left(\mathrm{KrV}, \mathrm{A}_{33} / \mathrm{B}_{49}\right)$. Time is thus one of the 'conditions of receptivity of our mind' ( $\mathrm{KrV}, \mathrm{A} 77 / \mathrm{IO} 2)$. To be precise, it is the form in which 'we intuit ourselves only as we are internally affected by ourselves' ( $K r V, \mathrm{~B}_{1} 56$, original emphasis). In short, 'inner sense' is 'nothing but the way in which the mind is affected by its own activity' ( $K r V, \mathrm{~B} 67-8)$. Many issues regarding inner sense require clarification: consider the familiar question of whether Kant recognizes 
a manifold of content over and above that received from outer sense. But what matters here is the primary claim regarding self-affection. For one clear instance of what Kant means, consider categorical synthesis, a spontaneous act which is both exercised on the spatial manifold and in which we thereby 'intuit ourselves only as we are internally affected' $\left(K r V, \mathrm{~B}_{1}{ }_{53}\right)$. Crucially, in line with the doctrine of inner sense, it is this act of self-affection which first produces an awareness of temporal succession.

[W] cannot even represent time itself without, in drawing a straight line (which has to serve as the external figurative representation of time), attending merely to the action of the synthesis of the manifold ... Motion, as the action of the subject (not as a determination of an object), consequently the synthesis of the manifold in space ... first produces the concept of succession. (KrV, B I $_{54-5}$; similarly B 292)

Kant's point is that it is the action of the subject, in drawing a line, which yields an awareness of succession. Unsurprisingly, the Analytic focuses on the sophisticated self-affection of rational agents. But I believe that Kant regards this basic model as applying much more widely. Specifically, Kant sees temporal succession in both rational and non-rational beings as the form in which those beings intuit their own determination of the spatial manifold. Of course, Kant's treatment of animals is often deeply unclear: for example, he occasionally denies that animals possess inner sense (V-MP-Li/Pölitz, 28: 276). I agree with McLear that the price of taking this kind of remark, which arises from the elision of apperception and inner sense, at face value is too high: inner sense is the form of time, and 'it seems scarcely credible to attribute conscious awareness of any sort to animals when that awareness is not temporally structured' (McLear 20I I: 9). But one can nevertheless discern Kant's position, at least in the Critical period, fairly clearly: time is the form in which beings intuit self-affection, and the principal case of such self-affection is the act of changing the scope of conscious awareness of the spatial manifold, an act which will occur in more or less sophisticated guises depending on the creature involved. This is the heart of what I called Kant's 'general theory'.

To support this reading, I will examine two key texts; I will then spell out the implications for nonconceptualism. The first text is the discussion of the synthesis of apprehension in the A Deduction.

Every intuition contains a manifold in itself, which however would not be represented as such if the mind did not distinguish 
the time in the succession of impressions on one another; for as contained in one moment no representation can ever be anything other than absolute unity. ( $\mathrm{KrV}$, A99)

The place to begin is the final clause. As contained in 'one moment', the intuition is an 'absolute unity'; elsewhere Kant refers to it as a 'synopsis' 'which contains a manifold' ( $\mathrm{KrV}, \mathrm{A97})$ and as a 'quantum', i.e. that which 'I can cognize immediately' (V-MP/Dohna, 28: 630). I agree with Tolley that the point about 'absolute unity' cannot be that intuitions given 'in one moment' are entirely unarticulated - or else it would be impossible to instantly see two things as standing next to each other (Tolley 20I3: I 22). Rather, it is that such 'absolute' empirical intuitions are not themselves products of synthesis; these empirical representations, for example the man standing in the field, are directly and immediately generated by our being affected through 'outer sense'. (One might think, separately, that the pure forms of space and time depend on some synthesis; my point here concerns individual empirical intuitions I return to the pure forms at the end of the section.) Such an absolute or instantaneous intuition 'contains a manifold in itself' because, like all intuitions, it is infinitely divisible ( $K r V$, A $\left.169 / \mathrm{B}_{21} \mathrm{I}\right)$. However, insofar as the intuition is considered at only a single point in time, this manifold is 'not represented as such', i.e. it is present but we are not conscious of it - precisely as in the example of the man's eyes in the Anthropology. The reason is that an awareness of the parts, i.e. a shift in the scope of conscious awareness, necessarily implies an awareness of succession: the manifold is thus only 'represented as such' insofar we 'distinguish the time in the succession of impressions' Why? The answer is that this is precisely the claim regarding the connection between consciousness and time that I discussed above: succession is the form in which we intuit our own act of 'attention', of shifting the scope of conscious awareness $\left(\mathrm{KrV}, \mathrm{B}_{\mathrm{I}} \mathrm{5}_{6}\right)$. Conversely in the absence of an awareness of succession, i.e. when dealing with an intuition 'as contained in one moment', we lack consciousness of its parts. In short, the 'synthesis of apprehension' is the process whereby I come to consciously represent the parts of something rather than merely to intuit them, i.e. to objectively perceive them in the language of $\mathrm{KrV}, \mathrm{A}_{32} 2 \mathrm{O} / \mathrm{B}_{376-7}$. Thus 'by the synthesis of apprehension I understand the composition of the manifold of an empirical intuition, through which perception, i.e. empirical consciousness of it (as appearance), becomes possible' $(\mathrm{KrV}, \mathrm{B} \mathrm{I} 60)$. Such changes of conscious awareness are acts intuited under the form of time: thus 'the apprehension of the manifold ... is always successive' $(\mathrm{KrV}$, AI $89 / B_{234)}$. 
The other text I want to adduce in support of my account is the treatment of magnitude in $K U$. There Kant begins by discussing the extent of the conscious spatial awareness that one has at a given instant, what one 'can grasp at a single glance' (in einem Blick fassen, $K U, 5: 254)$. Kant refers to this extent as the 'basic measure' and gives various examples of it, such as an area the height of a man $(K U$, $5: 256)$. In the case of rational agents, shifts in the scope of such conscious awareness are partly a function of the concepts I possess: when I acquire the concept of racism, for example, I attend to different aspects of the same scene. In animals, in contrast, the scope of conscious awareness, and the shifts in it, are determined by an imagination governed by natural laws $(K U, 5: 25 \mathrm{I}-2)$. We thus have two types of motion and two types of attention: rational and non-rational. So, as I read it, passages such as the following, whilst primarily concerned with apperceptive motion, are also speaking simultaneously of a broader phenomenon: 'I do not see how one can find so many difficulties in the fact that inner sense is affected by ourselves. Every act of attention can give us an example of this' ( $K r V, \mathrm{~B}_{15} 6$, original emphasis). This is precisely what I am claiming: the act of attention, of focusing in, which may take more or less sophisticated forms, affects inner sense, resulting in an awareness of succession $\mathrm{KrV}, \mathrm{B} 67-8)$. To put it another way, the 'motion of the subject', the act of shifting the scope of consciousness, may be more or less determined: in non-rational agents 'motion' is caused by natural laws, whilst in rational agents it may be self-initiated to a greater degree (spontaneity) or even to an absolute degree (autonomy).

Suppose the model I have outlined has something going for it; if one wishes to reject it, an alternative account of Kant's views on the scope of conscious awareness, motion, perception and so on would be needed. What are its consequences for nonconceptualism?

First, we have a better grip on the relation between animals and humans. As stated in section I, I remain neutral on how exactly the content of animal intentionality is to be understood, for example whether it is Russellian. But what we are dealing with is something more than mere sensation, which is deliberately placed on a lower level of Kant's 'ladder' $\left(\mathrm{KrV}, \mathrm{A}_{32} 20 / \mathrm{B}_{376}\right.$; Log, 9: 64-5). Instead, the animal's engagement with the world includes a conscious and unconscious representation of spatial entities within what Allais neatly calls an 'egocentric frame of reference or phenomenal field'. ${ }^{4}$ The dog sees the bowl as to its left and nearer than the wall; he then focuses in on its parts, perhaps the dark-coloured 
portion which he associates with food. In humans, the situation is more complex. Just as with the dog, our act of shifting the scope of conscious awareness to become aware of the parts of an empirical intuition necessarily generates an awareness of succession. Unlike the dog, however, those acts are governed by concepts: we possess 'rules for apprehension' ( $\mathrm{KrV}, \mathrm{AlO}_{3-4}$; Refl., I6: 557). In short, the very same basic framework that underlies empirical intuitions, perception, succession in the human case also underlies the nonconceptual intentionality of animals; the far-reaching and important differences between the two cases, such as concept possession, need to be seen against the backdrop of these shared structures. One way to express this is by distinguishing two notions of consciousness. The motion of non-rational subjects makes intuitional states conscious in the sense exemplified by the Anthropology's example of seeing the man at a distance and then gradually becoming conscious of the parts of his face. In rational beings, the manner in which we become conscious of the world is inter-defined with a second order capacity to become 'conscious of' our own representations, i.e. to be self-conscious or apperceptive. This does not mean, of course, that we typically go round thinking about representations; the claim is rather that when I become conscious of the table, I have a second-order awareness of the marks of that intuition as standing in various inferential relations, relations which I recognize are not simply a matter of my own psychological history, but are instead presumptively grounded in the thing and so presumptively valid for other agents too $(K r V$, Aio6, I26, BI42, Ai97/B242-3; GMS, 4: 4I2; Refl., I6: 663). ${ }^{5}$ But such concepts operate within the same underlying framework of intuition, attention, shifts of conscious awareness, inner sense, etc.

Second, we have a clearer view of how nonconceptual synthesis might work. Animal intentionality is based on the interaction between apprehensive synthesis and associative reproduction. This is because there must be some mechanism for allowing the successive intuitions generated by shifts in attention to inform each other - otherwise they would simply lie 'dispersed and separate in the mind' ( $K r V, \operatorname{Ar} 20)$. In animals, this mechanism is associative imagination $\left(K r V, \mathrm{AI}_{20}\right)$. As Kant puts it, 'if I consider myself as an animal', representations 'could still carry on their play in an orderly fashion, as connected according to empirical laws of association' (Br., I I: 52).

In rational agents, as I discuss in section 4 , there is a more sophisticated unifying mechanism in play - the understanding. Before getting to 
that, however, it is worth comparing my position with two prominent alternatives: Tolley's and Waxman's.

Tolley defends a version of nonconceptualism in which, whilst there are nonconceptual intuitions, there is no nonconceptual synthesis (Tolley 20I3). I absolutely agree with Tolley that there can be an intuitive intentional content which is not the product of synthesis: this is the 'absolute unity' of A99 (Tolley 2013: I 22). But I disagree on four issues. First, I regard this as an exceptional limit case. Both apprehension and association are basic activities, characteristic of a primitive capacity for investigating the world. I thus disagree with Tolley's view that nonsynthetic intentionality is the only form of nonconceptual representation recognized by Kant (Tolley 20I3: I2I-2). Second, Tolley's rejection of nonconceptual synthesis forces him to equate perception, as it figures in the discussion of apprehension in A99, with the type of reflective, secondorder awareness characteristic of Kantian concepts (Tolley 20I3: I IO, I 23-4). This intellectualist gloss on perception clashes directly with texts such as Log., 9: 64-5 and $K r V, \mathrm{~A}_{32} 20 / \mathrm{B}_{376-7}$ where the term clearly means merely conscious awareness. Another way to put the point is that Tolley's reading conflates the weak sense of 'consciousness' discussed in the previous paragraph with the strong, apperceptive sense. Third, Tolley states that his rejection of nonconceptual synthesis is based on passages such as $K r V$, $\mathrm{BI}_{\mathrm{I}} 30$, where Kant states that 'all combination is an action of the understanding' (Tolley 20I3: I2I-2). But it is going too far to say that such remarks 'stifle any hope for carving out space for a kind of synthesis that does not involve concepts' (Tolley 2013: I 22). One option is to stress that Kant is here defining 'understanding' in opposition to sensibility. Since sensibility is that which is purely passive $\left(K r V, \mathrm{~A}_{5} \mathrm{I} /\right.$ B75), it is possible that 'understanding' is being used broadly to encompass any active rearrangement of the manifold, and not just the sophisticated forms of such characteristic of rational agents - so, for example, Ar 20 identifies the imagination as 'an active faculty'. Another option is to accept that 'understanding' at BIzO does indeed refer to conceptual awareness, but to argue that what Kant really means is that combination across all forms of content, including that of the sensible manifold, may be determined by the action of the understanding. Again, this is not special pleading: many passages show how hard Kant was finding it to articulate his views (consider the vacillations over the status of the imagination and synthesis at $K r V, \mathrm{~A}_{7} 8$ and $\left.\mathrm{B}_{\mathbf{1}} 30\right)$. Finally, there is strong evidence from other writings that Kant allows animals associative synthesis (for example, Br., I I: 52; V-MP-LI/Pölitz, 28: 275-7; V-MP/ Dohna, 28: 689-90). Assuming that we must deny animals the reflective 
and inferential capacities of the 'I think' (Anth., 7: I 27) and thus concepts

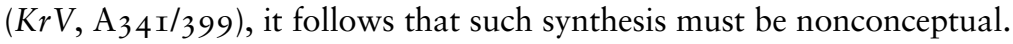
On balance, it thus seems right to recognize nonconceptual synthesis within Kant's philosophy. What I have tried to show is how closely tied such synthesis is to his general theory of perception, of consciousness, and of the awareness of succession.

Turning to Waxman's reading, there are again notable points of agreement: for example, I think he is right to present pure intuition as answering what is often known as the 'binding problem', i.e. the question of how multiple sensory data streams can be united in a 'super-field' (Waxman 20I3: 97). I am neutral on his distinctive appeal to a 'nondiscursive' apperception, although I am wary as to whether we have a good enough grip on this idea for it to do real explanatory work (Waxman 20I3: I4I). But he and I disagree on three fundamental points. First, Waxman sees sensibility, considered in abstraction from concepts, as radically impoverished. In the absence of concepts: 'sensibility contributes neither order nor relation to the manifolds of space and time, it can do nothing to differentiate and determine each space and each time' (Waxman 20I3: II). The result is what Waxman describes as Kant's 'self-created problem', namely that:

[E]xperience itself would be impossible if the sensible existents encountered in it were devoid of all spatial and temporal differentiation and determination; and since this is precisely what they lack given only the unity of sensibility made possible by pure sensible intuition, this want must be made good by pure understanding, by means of its pure concepts, or not at all. (Waxman 2013:368)

I agree that without conceptual capacities one cannot enjoy experience in the thick sense of 'cognition', nor represent 'objects' where that notion is defined in terms of rules (Waxman 20I3: 364). But it appears that Waxman also endorses the stronger view that sensibility by itself is unable to present relations such as egocentric distance, or to sustain the differentiation of items by spatiotemporal position: this alone makes sense of his talk of nonconceptualized appearances as 'devoid of all spatial and temporal differentiation and determination'. Yet that strong view renders it impossible to understand the behaviour of animals, which are evidently capable of distinguishing and tracking the closer of two food sources. Second, I believe that Waxman misidentifies the role of apprehension. For him, apprehension generates these impoverished appearances, 'devoid of all 
relation among themselves': this is his explicit gloss on Kant's claim at $\mathrm{KrV}$, AI 20 that its outputs are 'dispersed and separate' (Waxman 20I3: I 50). But Kant's point is more subtle. The outputs of apprehension typically include intuitions with relational spatial content: the dog sees 'at a glance' the intruder by the door $(K U, 5: 254)$. Such intuitions are dispersed only because shifts in conscious awareness generate, as described above, an experience of succession. Third, Waxman places an impossible burden on the understanding: 'only by grasping how very little Kantian sensibility is able to set in place ahead of the understanding can one hope to appreciate the hugeness of the void the latter is obliged to fill by means of its pure concepts' (Waxman: 20I3: I I 8, original emphasis). Suppose I perceive two pillars: why do I intuit them beside each other and not behind one another? It surely cannot be the understanding's task to determine this: the categories are compatible with either option. Dialectically, it is striking that Waxman justifies this as necessary for the success of the Deduction: granting such an extensive role to understanding constitutes 'Kant's sole and entire warrant' for 'the objective validity of the categories' (Waxman 20I3: 372). As I will show in sections $3 \mathbf{3}$, however, this is not the case.

To complete the overall story of this section, my discussion of empirical intuitions would need supplementation by a treatment of space and time as pure intuitions. That is, unfortunately, beyond this article, but one can see how that chapter might be told. Animals would have a primitive awareness of the pure forms within which individual empirical intuitions occur. This primitive awareness could be cashed in terms of open-ended motor intentional dispositions: insofar as the prey keeps running left, the animal will keep running left. Rational agents alone are able to develop more sophisticated representations of space and time as a whole, such as Newtonian mechanics.

Kant's 'general theory' as set out here generates certain systemic limitations on intuitive content - crudely, the price of shifts in conscious awareness is that the relevant intuitions are given as successive and thus 'dispersed and separate in the mind' $\left(K r V, A_{I} 20\right)$. To remedy this, some 'combination .... is therefore needed' $\left(K r V, A_{120}\right)$. I now turn to the distinctive combinatorial capacities of rational agents.

\section{Transition to the Deduction and the Principles}

This section introduces the relationship between the categories, the principles and nonconceptualism. I first make explicit some methodological assumptions, and then offer some preliminary remarks about the Deduction. 
It is a familiar point that many Kantian texts admit of both conceptualist and nonconceptualist readings. For example, the famous dictum that 'intuitions without concepts are blind' supports conceptualism if 'blind' is read as 'lacking intentional content' (Falkenstein 1995: 58). For nonconceptualists, however, the point becomes clear a few lines later when Kant states that only from the union of understanding and intuition can cognition arise: 'blind' thus simply means 'falling short of the higher standards required for cognition' where cognition implies both intuitions and concepts (Hanna 20II: 405). More generally, the nonconceptualist can always grant that high-level achievements require conceptual capacities, whilst insisting that a state might nevertheless remain an empirical intuition despite falling short of that standard. The same move is possible if one frames the debate in terms of 'objects': there are texts which clearly invite a reading on which objectivity is separable from conceptuality, as the nonconceptualist believes. For example: 'To make a concept, by means of an intuition, into a cognition of an object, is indeed the work of judgment; but the reference of an intuition to an object in general (die Beziehung der Anschauung auf ein Object überhaupt) is not' (Br., II: 3IO-II).

The question, of course, is how we should understand this notion of objectivity and how it relates to passages which align objects with rules and concepts ( $K r V$, A2OI/B246). Again one sees texts pushing both ways. The same point can even be made with respect to 'cognition' itself. Whilst the dominant usage in Kant's work is undoubtedly one according to which cognition requires both intuition and concepts, the Stufenleiter passage states that a cognition 'is either an intuition or a concept' (entweder Anschauung oder Begriff), phrasing which allows nonconceptualists like Hanna to claim that Kant is torn between a broad and narrow use of Erkenntnis, with only the latter requiring conceptual capacities (Hanna 2005: 256). To take one more case, passages such as $\mathrm{KrV}, \mathrm{A} 89-9 \mathrm{I} / \mathrm{B}_{\mathbf{2} 2-3}$ are prima facie clear endorsements of nonconceptualism. The issue is whether we should read them at face value or as mere possibilities that the Deduction ultimately shows to be incoherent (Hanna 20I I: 404-5; Griffith 20I0: I99). In short, the issue of Kantian nonconceptualism cannot be settled by any catalogue of texts since one's stance on any specific passage will both form and be formed by one's broader views on issues such as synthesis, the Deduction, the status of animals, etc.

I now want to turn to the Deduction. I cannot mention, let alone treat, each aspect of Kant's argument. Instead, I focus on one of its central aims, and 
one which is directly related to the question of nonconceptualism. The Deduction aims to establish the objective validity of the categories; more specifically, Kant aims to establish certain a priori, necessary and synthetic principles valid of 'all objects of experience' $\left(K r V, \mathrm{BI}_{\mathrm{I}} \mathrm{I}\right)$. As a transcendental argument, the Deduction proceeds by demonstrating that these principles are a necessary condition for something (A783/B8 I I). Let us call this something, whatever it is, Premise. Kant himself sometimes speaks of Premise in terms of 'experience', sometimes in terms of 'objects', but this alone does not advance matters since the nonconceptualist will simply claim that 'experience' and 'objects' here refer to sophisticated states, well beyond mere intentionality (so, for example, $K r V$, Aıо6, $\mathrm{B}_{1} 37$ ). But the following can surely be agreed by all: it is a necessary condition on Kant's argument being viable that Premise, whatever it is, is not itself more problematic than the categories. After all, the dialectical structure of Kant's transcendental argument requires that one begins from something which his opponents grant, and then progresses to some hitherto unnoticed condition of that. Furthermore, it seems reasonable to assume that those opponents to whom Kant is speaking include empiricists such as Hume (Prol., 4: 257; KrV, BI68). The result is an adequacy condition on the Deduction: Premise must be something which such empiricists either accept or can be brought to accept comparatively easily.

I will now sketch a simple proposal on which the Deduction, so read, remains entirely compatible with nonconceptualism: categorical synthesis is not necessary for empirical intuitions per se, but only for the representation of a special class of relations among such intuitions. In Kantian terms, they are necessary only for a certain mode of unification or synthesis. ${ }^{6}$ In short: 'The possibility of cognizing a priori through categories whatever objects may come before our senses, not as far as the form of their intuition, but rather as far as the laws of their combination are concerned $\ldots$ is to be explained' $\left(K r V, \mathrm{~B}_{159-60}\right.$, emphasis added).

Specifically, I think that the categories provide a way to re-establish complex relations among the necessarily successive perceptions generated by apprehension, as discussed in section 2. The same point can be expressed by distinguishing two senses of 'object'. ${ }^{7}$ Kant's system allows animals to perceive spatiotemporal particulars; such states thus have an 'intentional object' as that phrase is used in the phenomenological and analytic literature on the philosophy of mind. What I am denying is that they have an 'object'

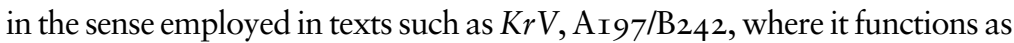
a term for those distinctive modes of categorical combination. ${ }^{8}$ 
To introduce this proposal, consider the case where it is most natural, the Second Analogy. In line with section 2, Kant begins by stating that ' $\mathrm{t}]$ he apprehension of the manifold is always successive' ( $K r V$, AI 89/B234). The question immediately arises as to how we are able to represent the difference between two relations: successive perception and perception of succession. Kant's answer is that we must represent the latter as governed by some form of causal bond. This exhibits precisely the dialectical structure I noted: it is effective against the empiricist given the plausible assumption that she recognizes our ability to at least represent the distinction between an event and a successive perception of two unchanged, simultaneously existing, objects. After all, debates between positivistic, projectivist and sceptical realist accounts of the Treatise are debates over what must be added to events in order to generate causality. ${ }^{9}$ As Longuenesse observes, 'Kant maintains that some representation of causal relation, rather than resulting - as Hume claimed from the repeated perception of generically identical successions of events, is presupposed in the very representation of any particular objective succession' (Longuenesse 2005: I43). ${ }^{\mathrm{IO}}$ In the case of animals, in contrast, it seems more reasonable to speculate that they possess empirical intuitions, a series of images of a ship for example, while lacking precisely the ability to posit certain sophisticated relations among those images, relations such as the distinction between subjective and objective succession. ${ }^{\text {II }}$ In short, the success of the Second Analogy as an anti-empiricist transcendental argument is compatible with nonconceptualism.

The Second Analogy is thus a natural fit with my approach. But one might worry that this very naturalness is problematic. ${ }^{\mathrm{I2}}$ After all, many Kantians, irrespective of their views on conceptualism, might be sympathetic to what I have said about that particular text. There are two points to be made. First, there are commentators who explicitly state that categorical synthesis is a necessary condition on the empirical presentation of spatiotemporal particulars (Griffith 2010: 194, Ginsborg 2008: 70). Even the limited remarks made so far suggest that they are mistaken - the Second Analogy presents causality as necessary only for the representation of specialised relations between such particulars. Second, I began with the Second Analogy because it is the easiest ground on which to run my proposal. As I discuss in section 4 , matters become really interesting when one expands it to the mathematical categories.

I have argued that this approach to the Deduction is compatible with nonconceptualism; animals may possess intuitive content in the complete absence of conceptual capacities. But it is important to stress, equally, the implications 
for the human case; insofar as humans represent the relevant relations, it follows that they necessarily deploy the categories. It is worth contrasting my approach to existing nonconceptualist attempts to accommodate the Deduction. Take the case of Allais: the fundamental difference between Allais and me concerns when and how the categories become necessary. She writes:

[T] he Deduction is specifically concerned with one aspect of cognition: the conditions under which we can apply concepts to objects in judgments ... in the Deduction, he wants to show that a priori concepts are necessary conditions of being able to apply empirical concepts in empirical judgments. (Allais 20II: IO2, original emphasis)

Kant was certainly sometimes attracted to this approach $(K r V$, AIII, A93/BI26). Furthermore, Allais's strategy has similarities to my own: both hold that the categories are necessary only for the representation of a 'special kind of unity' (Allais 20I I: I05). But there are crucial differences. For Allais the warrant for the application of the categories is that they are 'the conditions under which we can apply concepts to objects in judgments': the distinctive unity which the categories make possible is the unity characteristic of empirical concepts and related notions such as 'property' or 'general feature' (Allais 20II: IO3-4). As a result, Allais's view faces two difficulties. First, it damages the Deduction as a transcendental argument. Hume will not accept the premise of Allais's argument: he will argue, as Berkeley does, that there is no need to postulate anything like Kantian empirical concepts in the first place - all that is needed is a tendency to associate groups of particular images (Hume I978: I.I.7.7-8). Of course, Hume may be wrong about that. But my model shows the categories to be necessary for something that is not itself a philosophical hypothesis, but rather a basic datum of any recognisably human awareness of the world. 'No one', Kant states, will fail to recognize the difference between the ship and the house case $(\mathrm{KrV}, \mathrm{A}$ 990/B235); the sceptic might insist that we are universally mistaken, always seeing as successive what is really simultaneous, but she cannot plausibly deny that we have the resources to at least represent the distinction. Second, it is hard to see why the categories should be 'necessary conditions of being able to apply empirical concepts in empirical judgments' (Allais 20II: I02). Empirical concept formation certainly requires that objects and properties exhibit a reasonable degree of coherence $(\mathrm{KrV}$, Aroo-I). But why should it require anything as strong as the existence of causal laws? Of course, there is a long-standing debate over the strength of arguments like the Analogies. My point is that 
Allais's approach creates a structural problem insofar as it premises the categories on something bound to imply only a weaker result. One might respond by 'thickening' empirical concepts, but this will simply exacerbate the first difficulty: the more plausible it becomes that empirical concepts imply categorical order, the more the warranted application of those empirical concepts themselves becomes open to question. In sum, on my reading the categories are necessary for some achievement more basic than on Allais's account; I return to this at the end of section 4 .

\section{The Categories and Relational Synthesis: The Axioms}

The task now is to develop the proposal of section 3: I use the example of the categories of quantity as detailed in the Axioms. I choose the Axioms for several reasons: it is, for example, appealed to by Griffith in defence of conceptualism. ${ }^{\mathrm{I}}$ But the most important is that, whilst the text of the Axioms supports my claims, it also shows why Kant's position has been misunderstood. Specifically, Kant is torn between two lines of argument, a problem rooted in the distinction between the mathematical and dynamical categories, and one which explains some of the textual issues that obscure his nonconceptualism.

The Axioms aims to demonstrate that '[a]ll intuitions are extensive magnitudes' $(\mathrm{KrV}, \mathrm{B} 2 \mathrm{O2})$, or that '[a]ll appearances are, as regards their intuition, extensive magnitudes' ( $K r V$, AI6I). I use the former formulation, but I do not regard the two as differing significantly. Kant defines an extensive magnitude as follows: 'I call an extensive magnitude that in which the representation of the parts makes possible the representation of the whole (and therefore necessarily precedes the latter)' (KrV, AI62/ $\mathrm{B} 203)$. The issue in play is thus mereology. At the level of the pure forms of intuition, of course, the whole has priority over the parts $\left(K r V, \mathrm{~A}_{22} / \mathrm{B}_{3} 8\right)$. But here we are dealing with empirical intuitions, and Kant's claim is that, in such cases, the representation of the parts has explanatory priority over the representation of the whole. Now, as stated, I believe Kant developed two very different arguments for this claim. I label these the 'simple argument' and the 'complex argument', and I address them in turn.

The simple argument is encapsulated in the text beginning the A Edition of the Axioms:

I can represent no line to myself, no matter how small, without drawing it in thought, that is gradually generating all its parts from a point, and thereby first registering this intuition. ... every appearance as intuition is an extensive magnitude, as it can only 
be cognised through successive synthesis (from part to part) in apprehension. (KrV, $\mathrm{A}_{\left.162-3 / \mathrm{B}_{203}-4\right)}$

If we can represent an empirical intuition only by successively moving from 'part to part', it immediately follows, as the Axioms claims, that the representation of the parts has explanatory priority over the representation of the whole.

This simple argument aims to build on the theory of perception discussed in section 2: one sees the characteristic link between apprehension, i.e. changes in the scope of conscious awareness, and the awareness of succession. But the simple argument is fatally flawed. First, no justification is given for the premise that I 'can represent no line to myself, no matter how small, without ... generating all its parts from a point'. It seems phenomenologically undeniable that I can at least sometimes see a whole line at a single glance. Second, the simple argument leaves spatial perception radically underdetermined. Suppose I successively perceive a series of points. Why should I take them to form a straight line, as opposed to a bent one, if I can never see the line as a whole? Yet if I can represent the line as a whole, then why could I not do this prior to perceiving the parts? Third, the simple argument generates a regress since, given Kant's other assumptions, any part is divisible and so must itself have been arrived at by a successive perception of its parts. Fourth, even if the argument were sound, it is unclear how it would link to the categories: no direct mention has been made of them.

The underlying problem is that the simple argument relies on an extreme version of the account of perception outlined in section 2 . The point there was that shifts in the scope of conscious awareness, for example when perceiving the parts of something, necessarily create an awareness of succession. But this is perfectly compatible with the fact that we can, and initially do, simply perceive objects without needing to 'gradually generate' their parts; as I discussed in section 2, $K U$ appeals to the 'basic measure' precisely to emphasize that one may intuit something instantaneously, in a single glance $(K U, 5: 25 \mathrm{I}, 254) .{ }^{\mathrm{I} 4}$ Nevertheless, the simple argument remains important because it explains an otherwise troubling aspect of the Deduction. If the simple argument worked, it would entail that any intuition was an extensive magnitude just in virtue of the way it is perceived, i.e. through a successive synthesis of its parts. The only difference between a human and an animal would then be that the former was additionally capable of reflecting on and recognizing this fact. This, I suggest, is what Kant has in mind when he claims that 
the proof of the mathematical categories has a distinctive kind of 'immediate evidence' and 'intuitive certainty' ( $K r V$, AI60-2/BI99-20I). This same idea explains the prima facie conceptualist remarks found in $\$ 26$ of the Deduction. For example: 'all synthesis, through which even perception itself becomes possible, stands under the categories' $(\mathrm{Kr} \mathrm{V}$, BI6I). Clearly the nonconceptualist owes some account of this line. My suggestion is that it is driven by the simple argument, by the assumption that at least some categories might flow directly from the mere act of apprehension. But the simple argument is deeply flawed, and, as I now show, it does not reflect Kant's considered position.

I now outline the second proof of the Axioms: the 'complex argument'. The place to begin is $\$ 26$ of the Deduction where Kant discusses the distinctive unity which the categories bring to perception. Note that he is now talking specifically about himself, about human perception:

If I make the empirical intuition of a house into perception through apprehension of its manifold, my ground is the necessary unity of space and of outer sensible intuition in general. ... This very same synthetic unity, however, if I abstract from the form of space, has its seat in the understanding and is the category of the synthesis of the homogenous in an intuition in general, i.e. the category of quantity, with which that synthesis of apprehension, i.e. the perception, must therefore be in thoroughgoing agreement. $(K r V, \mathrm{BI} 62)$

Kant is explaining here how the category can act as a 'rule for apprehension', a mechanism for unifying the necessarily successive and so 'dispersed' perceptions generated by apprehension (Refl., I6: 557, $\left.\mathrm{KrV}, \mathrm{A}_{\mathrm{I}} 20\right)$. This immediately involves a far more sophisticated apparatus than the simple argument: note the references to homogeneity and the category of quantity. The same applies to the B edition of the Axioms, where the representation of determinate spaces and times is explained in terms of 'the composition of that which is homogenous ... Now, the consciousness of the homogeneous manifold in intuition in general, insofar as through it the representation of an object first becomes possible, is the concept of a magnitude' $\left(\mathrm{KrV}, \mathrm{B}_{2} \mathrm{O} 3\right)$.

I argued in section 3 that the categories re-establish complex relations among the successive perceptions generated by apprehension. In the Analogies, those relations are objective succession and simultaneity. I will now argue that in the Axioms they are certain mereological relations. 
Suppose a dog sees a space $X$ at $\mathrm{t} I$ : as described in $K U$, it intuits it at a single glance $(K U, 5: 254)$. At t2-t5 it becomes successively conscious of the various parts of $X$, exactly as described in section 2. Now the animal may associate these parts with the house originally seen at $\mathrm{t} \mathrm{I}$ : seeing one part brings to mind another. It may also react differently to different parts of an object: it licks only the corner of a bowl with food in it. But what the animal lacks is the ability to see the parts as parts, just as it lacks the ability to see something as a door ( $\mathrm{SvF}, 2$ : 59). It lacks this ability because representing that relation requires the categories of quantity: as Kant puts it, the concepts of part and whole lie under those categories (V-MP/Volckmann, 28: 423). To understand this and complete the argument, we need to look to the Schematism.

In the Schematism, Kant explains the schema for quantity in terms of the concept of number:

[T] he pure schema of magnitude, as a concept of the understanding, is number, a representation which compounds [zusammenbefaßt] the successive addition of unit to (homogeneous) unit. Number is therefore simply the unity of the synthesis of the manifold of a homogeneous intuition in general, a unity due to my generating time itself in the apprehension of the intuition. ( $K r V$, $\left.\mathrm{A}_{4} 42-3 / \mathrm{B}_{1} 82\right)$

I cannot address the general distinction between categories and their schemata, nor the issue of how exactly the three categories of quantity relate to the single schema of number. ${ }^{15}$ Instead, my interest is in the basic claim that number allows the 'compounding' of a manifold of homogeneous units. In section 2 I noted that Kant uses 'basic measure' to denote the scope of spatial consciousness at a given instant. But in rational beings, this same awareness plays an additional role: it serves as 'a measure or unity in estimating magnitude by numbers' (KU, 5:25I). To see the relevance, suppose now that I see spatial extent $X$ at tI. I perform the synthesis of apprehension, changing the scope of conscious awareness to generate a successive perception at $\mathrm{t} 2-\mathrm{t} 5$ of its smaller parts. So far this is just as with the dog. However, unlike the dog I possess the schema for number: I recognize the parts as 'homogeneous intuitions', i.e. I recognize them as falling under a common concept (V-MP-K $3 \mathrm{E} /$ Arnoldt, 29: 99I-2). Specifically, I am able to take $X$ and use it as a numerical base in terms of which the subsequent intuitions are conceptualized: $X$ is the 'basic measure' in both of the senses just noted. So at tI I represent a space as being size $X$, at t2 one as being size half $X$, 
at $\mathrm{t}_{3}$ one as being some small but indeterminate portion of $X$ and so on. Now to see the successive perceptions in these terms just is to represent mereological relations among them: for example, I can recognize that if I sum together the various parts it yields the original whole $X$. This 'summing together' is what the Schematism refers to as the act of 'compounding' made possible by the schema number. Recall: 'the pure schema of magnitude, as a concept of the understanding, is number, a representation which compounds the successive addition of unit to (homogeneous) unit' (KrV, $\mathrm{A}_{442-3} / \mathrm{BI}_{12}$; similarly $\mathrm{A}_{\mathrm{IO}}$ ).

It is this compounding of homogeneous units, i.e. successive parts conceptualized in terms of an original extent that serves as a numerical base, that animals cannot achieve. Whilst an image of one part may bring to their mind an image of the whole, they are unable to represent the fact that the whole is constituted out of those parts. ${ }^{\text {I6 }}$ They are unable to do this because they lack the relevant a priori schema, number. Thus the I793 Prize essay: 'the representation of a composite, as such, is not a mere intuition, but requires the concept of a composition (Zusammensetzung) ... that is not abstracted from intuitions ... but is a basic concept, and a priori at that' (FM, 20: 27I). Similarly in a I792 letter: 'Composition (Zusammensetzung) itself cannot be given by means of mere intuition and its apprehension, but only through the self-active combination of the manifold ... this combination and its function must be subject to rules a priori in the mind' (Br., I I: 376). In demonstrating these results, Kant validates the headline claim of the Axioms, that all intuitions are extensive magnitudes. But by itself that headline risks oversimplifying matters. What the Axioms actually shows is that, for any intuition, it is possible, given the schema for number, to recognize that it is composed by the sum of its parts.

I now turn to some objections to my view. First, one might counter that if a dog can perceive one item as to the left of another, surely it can perceive one space, such as the couch, within a larger space, such as the room, and so it can represent mereological relations. I am happy to grant this. My claim is not that any representation involving part and whole relations depends on the categories; the Aesthetic entails that even the ability to perceive empirical intuitions is in some sense dependent on an ability to represent space and time as wholes. Rather, my claim is that rational agents alone are able to represent the whole as constituted or composed by the sum of its parts. This is vital since it is a necessary condition on being disposed to believe certain very basic claims. Such claims include: if I replace a part with one of the same size, then the size of the whole will be 
unaffected; if I double the size of all parts, then the size of the whole will double; if one part is removed from a whole, then the size of the whole will be reduced by the size of that part. In short, composition is an a priori concept as claimed in the Prize essay. I say more on how common these dispositions are in response to the third objection below.

Second, one might question whether the proposal satisfies the demands imposed on the Deduction in section 3. The key issue here is balance: Kantian transcendental arguments need premises thin enough to be accepted by his opponents, but thick enough to yield substantive conclusions. Have I got the balance right? Is the part-whole relation I have identified both sophisticated enough that we can imagine an animal intentionality which lacks it, thus supporting nonconceptualism, and yet simple enough that it is assumed by Kant's empiricist opponents? The first conjunct is easily met: it is unproblematic to imagine a dog exhibiting differential reactions to the parts of an object, associating them together and yet lacking the notion of composition. But what of the second? Both Locke's and Hume's views on mereology are notoriously complex, and I cannot offer a full treatment of them here. But I can do enough to make the point. Consider, for example, this remark from the Treatise: 'There is another very decisive argument, which establishes the present doctrine concerning our ideas of space and time, and is founded only on that simple principle, that our ideas of them are compounded of parts, which are indivisible' (Hume I978: I.2.3.I2, emphasis added). 'Compounding' here is precisely the ability to represent multiple subparts as constituting a larger spatial whole, i.e. exactly that ability which the 'complex argument' of the Axioms shows is dependent upon the category of number. The result is that one can be a nonconceptualist and retain the core aim of the Deduction: namely, to provide a revolutionary rationalist response to empiricist sceptics.

Third, one might wonder if my account is really better off than that of Allais. I argued that Allais's reading of the Deduction was premised on something that Kant's opponents would not accept, namely empirical concepts. But why do the dispositional capacities I am assuming not face the same problem? After all, they sound like inferential abilities. Another way to put the point: even if Hume himself recognized an act of compounding, why can the empiricist not simply surrender that assumption? My response to both points is that the empiricist can plausibly reject explanatory hypotheses: he can, for example, reject the hypothesis that our treatment of instances of a given type is informed by a generic representation, such as a Kantian empirical concept, rather than a series 
of associated particular images. He can thus reject Allais's premise as discussed in section 3. But the empiricist cannot reject basic first-order data about human abilities, such as an ability to even represent the distinction between subjective and objective succession, between seeing the parts of a house one after another, and seeing a ship sailing downstream. Likewise, it is an unproblematic and everyday datum that normally functioning, adult humans do possess the dispositional abilities I emphasize: for example, a disposition to believe that if I double the size of all parts, then the size of the whole will double. Whilst perhaps not quite as obvious as the house/ship case, the presence of such dispositions can be established by empirical testing at a comparatively young age (I make no commitment as to exactly when - the issue is well modelled by developmental psychology experiments in which children play with blocks). ${ }^{17}$ Of course, the empiricist could simply dig her heels in and insist that we still do not in fact possess those abilities, just as she could insist we are not able even to represent any difference between the house and ship cases. But in so doing empiricism collapses into a merely dogmatic scepticism, which Kant has neither obligation nor ambition to refute. In Hume's own case, he would also have to abandon his classically empiricist attempt to explain our representation of space and times as wholes in terms of the sum of their parts.

I thus summarize the position reached. First, Kant is a nonconceptualist in that he allows for empirical intuitions in the complete absence of conceptual capacities; such intentionality is characteristic, for example, of animals. Second, I have sought to accommodate some of the motivations for reading Kant as a conceptualist. In particular, in the case of normally functioning, adult humans, empirical intuitions are necessarily accompanied by categorical synthesis. I have also offered an explanation as to why at least some passages suggest a cruder and more straightforward conceptualist picture, for example the first Edition of the Axioms. ${ }^{\text {I8 }}$

\section{Notes}

I This definition is in line with that used by Allais 2009: 384 .

2 All references are to Kant 1902 using the following abbreviations: Anth. = Anthropologie in pragmatischer Hinsicht; $\mathrm{Br} .=$ Briefe; $\mathrm{FM}=$ Welches sind die wirklichen Fortschritte [der] Metaphysik...?; GMS = Die Grundlegung zur Metaphysik der Sitten; $K r V=$ Kritik der reinen Vernunft; KU = Kritik der Urteilskraft; Log. = Logik; NG = Versuch, den Begriff der negativen Größen in die Weltweisheit einzuführen; Prol. = Prolegomena; Refl. = Reflexion; SvF = Die falsche Spitzfindigkeit der vier syllogistischen Figuren erwiesen $; \mathrm{V}-\mathrm{MP} /$ Dohna $=$ Metaphysik Dohna; V-MP-LI/Pölitz = Metaphysik L1 Pölitz; V-MP/Volckmann = Metaphysik 
Volckmann; V-MP-K 3 E/Arnoldt = Metaphysik K3 Arnoldt. I have consulted, although often modified, the translations in Kant I99I-.

3 'Consciousness' (Bewußtsein) is thus primarily a phenomenological term, identifying a form of qualitative awareness: a conscious representation is one that is 'illuminated' (Anth., 7: I35). Unconscious intuitions retain their representational structure but are 'obscure', with the result that we need to infer to our possession, rather than having an immediate phenomenological awareness, of them (Anth., 7: 135; NG, 2: I9I).

4 Allais 2009: 408 .

5 It is because of this ambiguity that some pre-Critical texts (e.g. V-MP/Dohna, 28: 689-90), deny animals 'consciousness' (for helpful discussion see McLear 20II).

6 The reference to 'relations' includes more than the three relational categories; my use thus mirrors Kant's own distinction between 'the synthetic unity of the manifold' and the individual category of unity $\left(K r V, \mathrm{~B}_{13} \mathrm{I}\right)$.

7 I do not think that the Gegenstand/Objekt distinction maps this divide, nor do I think that Kant deploys that distinction with any real uniformity (here I agree with Longuenesse I998: III).

8 As detailed in section 3, a similar distinction between two senses of 'object' is made by Allais - but the substance of my position is very different.

9 Without this assumed ability to identify objective succession, the Humean world would collapse into incoherence. Suppose I repeatedly see two doors, A and B, as I walk upstairs, and that I then see the same doors in the reverse order whenever I walk back down: without a capacity to recognize them as simultaneously existing, which for Hume is of course still delivered by imagination (Hume I978: I.2.4.24), I would be forced to regard A and B as both cause and effect of each other.

Io I differ from Longuenesse, however, on the key issue of animals (Longuenesse I998: 208n.).

I I One might argue that an animal can draw this distinction via its proprioceptive feeling of bodily motion. I am sympathetic to this, but it marks a fundamental departure from a Kantian approach: it suggests that one might recognize an event without seeing it as caused simply by bodily orientation.

I2 Thanks to an anonymous referee for pressing this.

I3 Griffith 20IO: 2I3-I4.

I4 Kant is often criticized for an implausible 'data atomism' (Beck I978: I44). KU shows this is unfair; but the simple argument explains the charge.

I 5 I agree that 'it is clear that the concept of magnitude is in some way intended to play the role of all three quantitative categories' (Sutherland 2004: 432).

I6 To be precise, my claim is not that possession of the schema for number is itself sufficient for this special representation of the whole but rather that it is necessary: one will need a sophisticated ability to re-identify spatial locations over time, something that is made possible by the schema for substance. One sees here how interlinked the various Kantian categories are, with each contributing one aspect to a unified picture of rational, sensible cognition; treatment of substance is, however, beyond this article.

I7 There is a large experimental literature on these issues, often influenced by Piaget; for a recent overview focussing on block play and the presence or absence of the relevant skills in three year olds see Verdine et al. 20I3.

I 8 I am very grateful to Lucy Allais, John Callanan, Colin McLear, Dennis Schulting, Nick Stang and Clinton Tolley for discussion and comments on this material. I am also indebted to the editor and two anonymous referees for their extremely helpful remarks on an earlier draft. 


\section{References}

Allais, L. (2009) 'Kant, Non-Conceptual Content and the Representation of Space'. Journal of the History of Philosophy, 47, 383-4I3.

- (2OII) 'Transcendental Idealism and the Transcendental Deduction'. In D. Schulting and J. Verburgt (eds), Kant's Idealism (London: Springer), pp. 9 I-Io8.

Beck, L. W. (r978) Essays on Kant and Hume. New Haven: Yale University Press.

Bowman, B. (20II) 'A Conceptualist Reply to Hanna's Kantian Non-Conceptualism'. International Journal of Philosophical Studies, I9, 4I 7-46.

Falkenstein, L. (I995) Kant's Intuitionism. University of Toronto Press.

Ginsborg, H. (2008) 'Was Kant a Nonconceptualist?'. Philosophical Studies, I37, 65-77.

Griffith, A. (2010) 'Perception and the Categories'. European Journal of Philosophy, 20, $193-222$.

Grüne, S. (20II) 'Is there a Gap in Kant's B Deduction?'. International Journal of Philosophical Studies, I9, 465-90.

Hanna, R. (2005) 'Kant and Nonconceptual Content'. European Journal of Philosophy, I3, 247-90.

- (20II) 'Kant's Non-Conceptualism, Rogue Objects, and the Gap in the B Deduction'. International Journal of Philosophical Studies, I9, 399-4I 5.

Hume, D. (1978) A Treatise of Human Nature, ed. L. A. Selby-Bigge. 2nd edn, text revised by P. H. Nidditch. Oxford: Clarendon.

Kant, I. (1902-) Kants Gesammelte Schriften. Berlin: de Gruyter.

- (I99I-) The Cambridge Edition of the Works of Immanuel Kant, ed. P. Guyer and A. Wood. Cambridge: Cambridge University Press.

Longuenesse, B. (1998) Kant and the Capacity to Judge. Princeton: Princeton University Press.

McLear, C. (20I I) 'Kant on Animal Consciousness'. Philosophers' Imprint, I I, I-I6.

Posy, C. (2000) 'Immediacy and the Birth of Reference in Kant'. In G. Sher and R. L. Tieszen (eds), Between Logic and Intuition (Cambridge: Cambridge University Press), pp. I $55-85$.

Speaks, J. (2005) 'Is there a Problem about Nonconceptual Content?'. Philosophical Review, I I 4, 359-98.

Sutherland, D. (2004) 'The Role of Magnitude in Kant's Critical Philosophy'. Canadian Journal of Philosophy, 34, 4I I-42.

Tolley, C. (2013) 'The Non-Conceptuality of the Content of Intuitions'. Kantian Review, I8, I07-36.

Verdine, A., et al. (2013) 'Deconstructing Building Blocks: Preschoolers' Spatial Assembly Performance Relates to Early Mathematical Skills'. Child Development, 4O, I-I4.

Waxman, W. (2013) Kant's Anatomy of the Intelligent Mind. Oxford: Oxford University Press. 